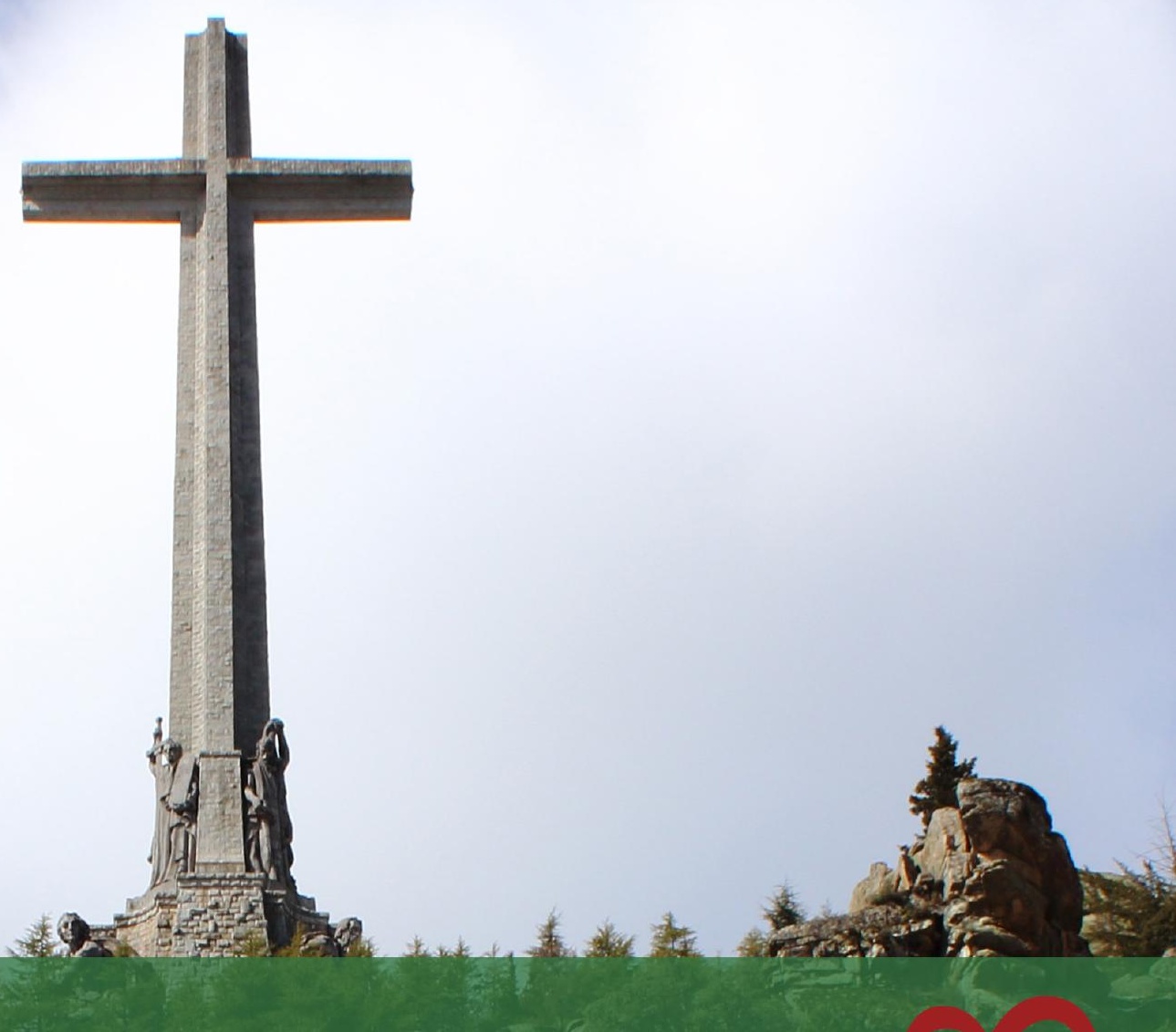

Revista digital de Ciencia y Didáctica de la Historia

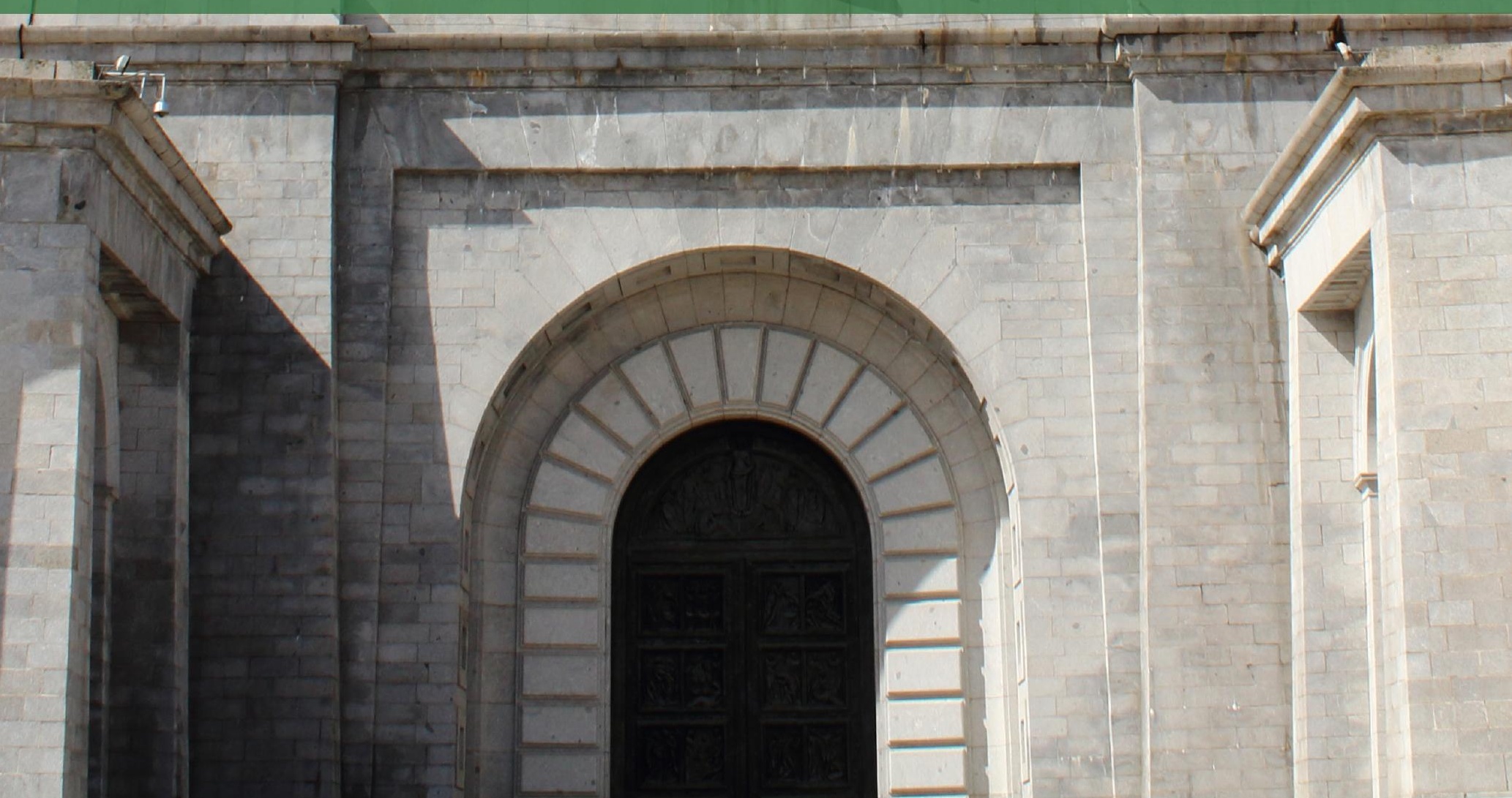




\section{Panta Rei \\ Revista Digital de Ciencia \\ y Didáctica de la Historia}

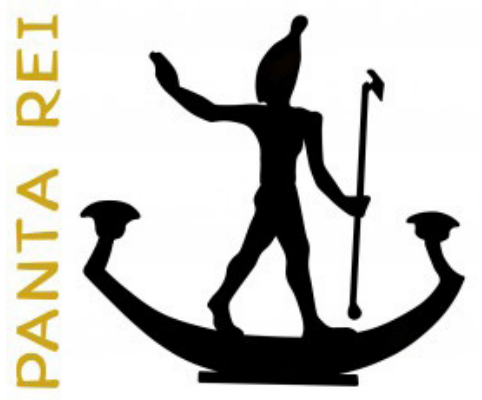

\section{8}

Revista anual

Fecha de inicio: 1995

Revista Panta Rei. pantarei@um.es

Edita:

Centro de Estudios del Próximo Oriente y la Antigüedad Tardía - CEPOAT

Edificio Universitario Saavedra Fajardo.

Universidad de Murcia

C/ Actor Isidoro Máiquez, 9

30007 - MURCIA - ESPAÑA

Teléfono: (+34) 868883890

cepoat@um.es

Web: www.um.es/cepoat/pantarei

Edición 2018

ISSNe: 2386-8864

ISSN: 1136-2464

Depósito legal: MU-966-1995



En Portada: Valle de los Caídos, Madrid. (Fotografía de: Adrián Rosell Lucas).

Responsables de los textos: Sus autores.

Responsable de la presente edición: Consejo Editorial Panta Rei. 


\section{CONSEJO DE REDACCIÓN}

\section{Coordinador editorial}

Egea Vivancos, Alejandro

[Didáctica de las Ciencias Sociales, UMU]

\section{Editores}

Botí Hernández, Juan Jesús

[CEPOAT, UMU]

Jiménez Vialás, Helena

[UMU]

López Muñoz, Damaris

[UJA]

Meseguer Gil, Antonio José

[CEPOAT, UNED]

Sáez Giménez, David Omar

[CEPOAT, UMU]

Sánchez Mondéjar, Celso Miguel

[Patrimonio Inteligente]

\section{Secretaria}

Arias Ferrer, Laura

[Didáctica de las Ciencias Sociales, UMU]

\section{Responsable informático}

Martínez García, José Javier

[CEPOAT, UMU]

\section{Traducción y corrección lingüística}

Martínez Martínez, Cristina

[Sociedad Española de Lenguas Modernas]

Albaladejo Albaladejo, Sara

[ISEN, UMU]

\section{CONSEJO ASESOR}

Adroher Auroux, Andrés María [Arqueología, Universidad de Granada]

Albero Muñoz, $\mathrm{M}^{\mathrm{a}}$ del Mar $\left[\mathrm{H} .^{\mathrm{a}}\right.$ del Arte, Universidad de Murcia]

Alia Miranda, Francisco [Historia Contemporánea, UCLM]

Arciniega García, Luis [Historia del Arte, Universidad de Valencia]
Barrio Barrio, Juan Antonio [Historia Medieval, Universidad de Alicante]

Castellano i Solé, Núria [Egiptología, Schola Didàctica Activa S.L.]

Chapman, Arthur [History Education, University College of London, Reino Unido]

Cid López, Rosa María [Historia Antigua, Universidad de Oviedo]

Cobacho López, Ángel [Derecho, Universidad de Murcia]

Cuenca López, José María [Didáctica de las Ciencias Sociales, Universidad de Huelva]

Egea Bruno, Pedro $\mathrm{M}^{\mathrm{a}}$ [Historia Contemporánea, Universidad de Murcia]

Feijoo Martínez, Santiago [Arqueología, Consorcio Ciudad Monumental de Mérida]

García Atienzar, Gabriel [Prehistoria, Universidad de Alicante]

Ginestí Rosell, Anna [Filología Clásica, Katholische Universität Eichstätt-Ingolstadt]

González Monfort, Neus [Didáctica de las Ciencias Sociales, Universidad Autónoma de Barcelona]

González Soutelo, Silvia [Arqueología, Universidad de Vigo]

Haber Uriarte, María [Prehistoria, Universidad de Murcia]

Hernández de la Fuente, David [Historia Antigua, Universidad Complutense]

Hutson, Scott R. [Anthropology, University of Kentucky, EEUU]

Igual Luis, David [Historia Medieval, UCLM]

Irigoyen López, Antonio [Historia Moderna, Universidad de Murcia]

Jover Maestre, Francisco Javier [Prehistoria, Universidad de Alicante]

Mahony, Simon [Digital Humanities, University College of London, Reino Unido]

Marsilla de Pascual, Francisco Reyes [Técnicas historiográficas, Universidad de Murcia]

Martínez-Burgos García, Palma [H. ${ }^{\text {a }}$ del Arte, UCLM]

Mathis, Christian [Didaktik der Geschichte, PH Zürich]

Miralles Maldonado, José Carlos [Filología Clásica, Universidad de Murcia]

Molina Gómez, José Antonio [Historia Antigua, Universidad de Murcia]

Mónica Ghirardi [Historia Moderna, Universidad Nacional de Córdoba, Argentina]

Navarro Espinach, Germán [Historia Medieval, Universidad de Zaragoza]

Noguera Celdrán, José Miguel [Arqueología, Universidad de Murcia]

Ortiz Heras, Manuel [Historia Contemporánea, UCLM]

Panzram, Sabine [Historia Antigua, Universität Hamburg]

Pérez Molina, Miguel Emilio [Filología Clásica, Universidad de Murcia]

Prados Martínez, Fernando [Arqueología, Universidad de Alicante]

Sánchez Ibáñez, Raquel [Didáctica de las Ciencias Sociales, Universidad de Murcia]

Sancho Gómez, Miguel Pablo [Educación, UCAM]

Victoria Moreno, Diego [Historia Contemporánea, UNED]

Vilar García, María José [Historia Contemporánea, Universidad de Murcia]

Vivas Sainz, Inmaculada [H. ${ }^{\text {a }}$ del Arte, UNED]

Zamora López, José Ángel [Próximo Oriente Antiguo, CCHS-CSIC] 

Artículos

El estilo decorativo en las primeras producciones cerámicas en el valle del río Vinalopó (Alicante).

Silvia Martínez Amorós.

Límites históricos del Ateísmo: increencia en la Grecia Antigua.

Ramón Soneira Martínez. .33

Dynamics of Power: an Architectural Reading of the Concentration of Power (Ullastret, 4th-3rd Century BC).

David Jesús Cebrián Martínez.

La mujer como exemplum. Subversión, desafío y resistencia en Valerio Máximo.

Lidia González Estrada.

The narrative framing of violence in teaching resources about the Spanish Conquest of America.

Ángela Bermúdez Vélez y Diego Argumero Martínez.

Modelos de conciencia histórica en el alumnado de Educación Secundaria: tradición, simbología y contextualización en torno a los restos del franquismo.

Diego Miguel-Revilla y María Sánchez Agustí.

La importancia de la contextualización curricular en la enseñanza de la Historia en México.

Enrique Bautista Rojas.

Experiencia didáctica para la enseñanza de la historia contemporánea a través de las fuentes en Educación Superior.

Nayra Llonch-Molina y Verónica Parisi-Moreno 161

\section{Reseñas}

Prados, F., Jiménez, H., Martínez, J.J. (Eds.) (2017). Menorca entre fenicis i púnics / Menorca entre fenicios y púnicos. Murcia: Centro de Estudios del Próximo Oriente y la Antigüedad Tardía de la Universidad de Murcia. 320 págs.

Pete Missingham

Bravo Bosch, M. J. (2017). Mujeres y símbolos en la Roma Republicana. Análisis jurídico-histórico de Lucrecia y Cornelia. Madrid: Dykinson. 333 págs.

Borja Méndez Santiago.

Karp, M. (2016). This Vast Southern Empire: Slaveholders at the Helm of American Foreign Policy. Cambridge: Harvard University Press. 360 pages.

Kevin Caprice.

Livi-Bacci, Massimo (2012). A Short History of Migration. Cambridge: Polity Press. 157 pages.

Alejandro Salamanca Rodríguez. 189

Normas de publicación/Publishing rules 



\title{
Experiencia didáctica para la enseñanza de la historia contemporánea a través de las fuentes en Educación Superior
}

\author{
Teaching Experience to Teach Late Modern History through Historical \\ Sources in Higher Education
}

Recibido: $14 / 02 / 2017$

Aceptado: $11 / 01 / 2018$

Llonch-Molina, Nayra ${ }^{1}$

Universitat de Lleida

Parisi-Moreno, Verónica²

Universitat de Lleida

Para citar este artículo: Llonch-Molina, N. y Parisi-Moreno, V. (2018). Experiencia didáctica para la enseñanza de la historia contemporánea a través de las fuentes en Educación Superior. Panta Rei. Revista Digital de Ciencia y Didáctica de la Historia, 161-176.

ISSNe: $2386-8864$

DOI: $10.6018 /$ pantarei/2018/8

\section{Resumen}

El presente trabajo muestra una experiencia de innovación docente en didáctica de la historia. La experiencia se llevó a cabo en el Grado de Educación Primaria y se basó en el uso combinado de fuentes primarias y recursos digitales, con el objetivo de desarrollar un modelo alternativo de enseñanza-aprendizaje de la historia que fomentara competencias de pensamiento histórico. El estudio de caso realizado desvela que dicha experiencia de innovación docente permite que los maestros en formación inicial pongan en práctica contenidos conceptuales y procedimentales determinantes para la adquisición de contenidos y de metodologías de enseñanza-aprendizaje de las Ciencias Sociales y la Historia.

\section{Palabras clave}

Didáctica de la historia, habilidades de pensamiento, usos de la tecnología en la educación, fuentes primarias, educación en valores.

\begin{abstract}
This paper presents an experience of teaching innovation in didactics of history. The experience was carried out in initial teacher training and was based on the combined use of primary sources and digital resources, with the aim of developing an alternative teaching-learning model of history that fosters historical thinking competences. The work done by the participants evidences that the experience allows teachers in initial training to put into practice conceptual and procedural contents that are decisive for the acquisition of both contents and teaching-learning methodologies of the Social Sciences and History.
\end{abstract}

1 Para contactar con la autora: Nayra Llonch-Molina. Universitat de Lleida. nayra.llonch@didesp.udl.cat. 2 Para contactar con la autora: Verónica Parisi-Moreno. Universitat de Lleida. veronica.parisi@didesp.udl.cat. 


\section{Keywords}

History education, thinking skills, technology uses in education, primary sources, values education.

\section{Introducción: las fuentes primarias en las aulas universitarias}

Este trabajo presenta una experiencia de innovación docente que fue implementada en el curso 2013-2014 en la asignatura "Didáctica de las ciencias sociales - Historia general de Europa", asignatura obligatoria de tercer curso del Grado de Educación Primaria de la Facultad de Educación, Psicología y Trabajo Social de la Universidad de Lleida (UdL). Se trata, por tanto, de una experiencia de enseñanza-aprendizaje de la Historia y otras Ciencias Sociales en formación universitaria que tiene como objetivo último mostrar la potencialidad del trabajo con fuentes primarias (Gómez, Ortuño y Molina, 2014; Inarejos, 2017; Prieto, Gómez y Miralles, 2013) para generar un conocimiento de la historia distinto al aprendizaje por recepción (Gómez y Rodríguez, 2014). El propósito era que los alumnos conocieran de primera mano y de manera vivencial dicho potencial, útil tanto para crear su propio conocimiento del pasado y mejorar sus competencias de pensamiento histórico (Gómez y Miralles, 2015; Santisteban, 2010; Santisteban, González y Pagès, 2010) como para poder aplicarlo como metodología de enseñanza en su futuro profesional y fomentar dichas competencias en el alumnado de educación primaria (Éthier, Demers y Lefrançois, 2010; Sáiz y Gómez, 2016).

La actividad educativa propuesta a los alumnos que se encontraban en la fase de formación inicial de maestros consistía en la creación de una pequeña exposición que tendría como base las fuentes primarias (objetos, documentos escritos, fotografías, testimonios orales, etcétera) que los alumnos tuviesen a su alcance. La duración de la actividad sería de 7 semanas, durante las cuales la profesora iría encomendando diversas tareas mediante las cuales los alumnos adquirirían los conocimientos, destrezas y técnicas necesarias para la materialización de la exposición. Estas tareas configurarían, a su vez, el material que serviría para evaluar el proceso de trabajo de los alumnos. La exposición, que estaría comisariada por los mismos alumnos con supervisión de la profesora, giraría en torno a un tema escogido por el grupo-clase y tendría lugar en algún espacio al aire libre del campus de la UdL. Además, la exposición sería de carácter efímero, pues tendría la duración de solo un día. Por otra parte, aunque la base de la exposición serían fuentes primarias del pasado, la principal característica de su presentación museística sería la incorporación del teléfono móvil como herramienta comunicativa, de manera que el público visitante, además de ver las piezas expuestas, podría escanear con sus teléfonos móviles unos códigos QR (Quick Response) situados junto a las piezas. De este modo, el público podría ampliar la información acerca de los objetos expuestos mediante recursos digitales elaborados previamente por los mismos autores de la exposición, es decir, los alumnos.

\section{Marco teórico: la didáctica del objeto como recurso para la enseñanza-aprendizaje de la historia}

La propuesta educativa que presentamos se basa, en primer lugar, en el uso de fuentes primarias, es decir, aquellas que se produjeron de forma simultánea a los acontecimientos sobre los que nos informan. Hay que tener en cuenta que estas fuentes pueden ser de naturaleza muy diversa (Prats y Santacana, 2011): fuentes materiales (objetos, edificios, obras de ingeniería...), fuentes escritas (epístolas, actas de bautismo y de defunción, periódicos, etc.), fuentes gráficas e iconográficas (pinturas, grabados, fotografías, ilustraciones...) y orales, entre otras. De acuerdo con Prats y Santacana (2011), los objetos son fundamentales para el conocimiento acerca de una cultura, actual o pretérita, ya que en ellos se reflejan las formas de vida de los grupos humanos a quienes pertenecen o pertenecieron, su grado de desarrollo, sus actividades productivas, sus creencias o el contexto histórico en el que dicha cultura se sitúa, entre otros. En definitiva, según los 
autores, las fuentes primarias son "la voz" de los hombres y mujeres del pasado.

De hecho, desde la década de 1990, muy especialmente en el ámbito anglosajón, y con antecedentes notorios en las décadas anteriores (Adams y Miller, 1982; Schools Council, 1972), se ha producido un aumento de estudios que se centran en el uso de fuentes objetuales en la enseñanza de la historia, lo que demuestra su potencial para el proceso de construcción del conocimiento histórico y la comprensión histórica en el contexto del aula. Muchos de estos estudios se basaron en las ideas expresadas por Durbin, Morris y Wilkinson (1996), donde los autores presentan una serie de factores que justifican el uso de objetos en las aulas de distintos niveles educativos, destacando la potencialidad de su uso para el desarrollo del pensamiento y comprensión históricos. Los autores sostienen que el análisis y la interpretación de los objetos es muy diferente de la explotación de otras fuentes primarias. Solamente con los objetos se pueden observar detalladamente ciertos aspectos como el tamaño, el peso, la forma, la precisión del color... Mediante los objetos también podemos emplear los demás sentidos y despertar sensaciones a través del olfato, el tacto, la temperatura... Por otra parte, los objetos de hoy nos ponen en contacto con objetos reales del pasado y, por lo tanto, permiten un cierto acceso a las experiencias de otros tiempos. Durbin, Morris y Wilkinson (1996) afirman asimismo que el uso de fuentes objetuales contribuye al aprendizaje activo, al acceso a la información que no está escrita, a la valoración de los objetos que nos rodean y también promueve experiencias sensoriales, táctiles y de percepción de las tres dimensiones, lo que contribuye, a su vez, a estimular la motivación, la curiosidad, la investigación y la voluntad de saber. Para los autores, el uso de fuentes objetuales refuerza, además, el desarrollo de habilidades transversales de comunicación y lenguaje a través de la descripción de ejercicios que utilizan verbos, adjetivos y vocabulario diverso en cuanto a la forma (¿cómo es?), los materiales (¿de qué está hecho?) o su función (¿para qué sirve?). Además, su uso permite cuestionar o formular preguntas, formular hipótesis, estimular el debate y la expresión oral, etc. También Cooper $(1995,2005)$ señala que es importante que los niños/as aprendan a observar los objetos para disfrutar de ellos y resalta su potencial como generadores de preguntas sobre su identificación, su función, las necesidades que llevaron a su producción, su "edad" o antigüedad, su uso, el impacto que el objeto pudo tener en la vida de quienes lo usaron, etc. (Cooper, 2005). Otros trabajos más actuales y que siguen líneas similares a las expuestas son los de Smardz y Smith (2000), Murphy (2005), Levstik, Henderson y Schlarb (2008), Corbishley (2011) y Levstik, Henderson y Lee (2014), la mayoría de ellos desde una perspectiva arqueológica, hecho que pone de manifiesto que la didáctica del objeto en las aulas se desarrolla principalmente a través de objetos arqueológicos.

En la línea de investigación anglosajona varios estudios han demostrado que el uso de fuentes objetuales por parte de los estudiantes contribuye al desarrollo de la comprensión histórica, a la adquisición de conceptos históricos y al desarrollo de conceptos fundamentales relacionados con el tiempo histórico como la cronología, el cambio, la continuidad y el progreso, así como la empatía histórica (Alvarado y Herr, 2003; Harnett, 2006; Hawkes, 1996; Hoodless, 1996; Nulty 1998; Seixas, Morton, Colyer y Fornazzari, 2013). Algunos de estos estudios destacan también la importancia del uso de objetos en el aula no solo para analizar la comprensión histórica y temporal de los estudiantes, sino también para desarrollar un aprendizaje activo de la historia.

Estudios similares llevados a cabo en otros lugares de Europa corroboran esta triple función del trabajo con objetos en el aula: desarrollo de competencias vinculadas al aprendizaje de la historia, desarrollo de competencias relacionadas con el lenguaje y constatación de un trabajo más activo e incluso significativo para el aprendizaje del alumno (Vella, 2010 y 2011).

En Portugal se han llevado a cabo varios estudios utilizando los objetos como una estrategia de enseñanza en el aula (Fernandes, 2009; Ribeiro, 2002; Solé, 2012a, 2012b; Solé y Llonch, 2016) y en el contexto del museo (Pinto, 2012). Ribeiro (2002) realizó un estudio descriptivo con estudiantes de 10 y 11 años en el contexto del aula, donde utilizaba objetos arqueológicos de época prehistórica y romana, con el fin de analizar la progresión de pensamiento arqueológico de los estudiantes. Se encontró que los estudiantes mostraron una mayor dificultad para realizar inferencias a partir de objetos arqueológicos prehistóricos que a partir de objetos romanos, sobre todo por la dificultad e 
incluso incapacidad de identificación y reconocimiento de la función de estos objetos extraños a sus experiencias. También hay que destacar el estudio de Aguiar (2015) que trata de analizar cómo los kits de objetos que el Museo de Maia lleva a las escuelas en el proyecto "Ver, tocar y sentir a Maia" (patrocinado por el Museo de Historia y Etnología de la Tierra de Maia) son recursos y estrategias cruciales de mediación patrimonial en museos, creando espacios para experiencias personales y educativas productivas que impulsen un aprendizaje efectivo, promoviendo memorias y recuerdos únicos también en las escuelas.

También existen en España diversos trabajos tanto de teorización sobre la importancia de los objetos como herramienta para la enseñanza-aprendizaje de la historia (Bardavio y González, 2003; Prats y Santacana, 2011; Santacana y Llonch, 2012), como estudios sobre su aplicación en educación infantil (Cuenca y Estepa, 2005; Mendioroz-Lacambra, 2016), primaria (Llonch y Molina, 2012) y secundaria, donde destacamos el trabajo realizado por Egea y Arias (2015) en el marco del "Proyecto innovación docente IES Arqueológico". En él se puso en práctica una serie de propuestas que utilizan la didáctica del objeto y la metodología arqueológica para la enseñanza de la historia. El proyecto responde a la pregunta: “¿Cómo se pueden introducir elementos del patrimonio arqueológico en las clases de una manera activa y significativa?" Para ello se sirven de simulaciones de excavaciones arqueológicas, llevan fuentes arqueológicas a los centros educativos y facilitan que el museo se abra a los centros. Precisamente Arias y Egea, junto con distintos autores, son, en el ámbito nacional, quiénes en el último quinquenio han trabajado más la didáctica del objeto, especialmente arqueológico, en la enseñanza tanto reglada como no reglada y tanto en Educación Infantil, como Primaria y Secundaria (Arias, Casanova, Egea, García y Morales, 2016; Egea y Arias, 2013). A nivel de educación universitaria, concretamente en formación de maestros, existen también diversas experiencias educativas basadas en la didáctica del objeto (Llonch, 2017; Llonch, Alonso y Benito, 2015; Llonch y Parisi-Moreno, 2016).

A nivel didáctico, "el uso de objetos fomenta la observación, la comparación, la deducción y otras habilidades" (Prats y Santacana, 2011, p. 13). Para Santacana y Llonch (2012), existen los siguientes argumentos de carácter didáctico a favor de enseñar con los objetos:

1. Fijan la imagen del concepto: los objetos se pueden observar desde múltiples perspectivas y por ello permiten relacionar la imagen del objeto con el concepto que se quiere trabajar. Además, el objeto actúa como un elemento de referencia, permitiendo que el alumno se exprese mejor.

2. Captan la atención del alumnado, pues se sienten atraídos por la posibilidad de trabajar mediante un soporte material. Más aún, cuando este soporte no es fácilmente reconocible por los alumnos y permite la introducción de cuestiones enigmáticas acerca del objeto.

3. Permiten desarrollar diversos métodos, ya que fomentan los procesos hipotético-deductivos así como las inducciones.

4. El uso de objetos provoca situaciones empáticas y fomenta la imaginación.

5. Son inclusores de la mente, por tanto, son útiles para que los alumnos vinculen la nueva información a la ya existente en su estructura cognitiva.

6. Activan la mente de tal manera que al recurrir a un objeto se activa una cadena de conceptos relacionados al objeto, lo cual permite establecer una secuencia entre el objeto y el sistema conceptual.

7. Son un soporte real, lo cual es muy importante en el contexto en que nos encontramos, donde la virtualidad empieza a sobresalir por encima de la materialidad.

Tal y como afirman Prats y Santacana (2011, p. 13), "es conveniente enseñar al alumnado a buscar y clasificar las fuentes del pasado" puesto que la clasificación es una importante técnica de aprendizaje en el aula. En este sentido, el alumno debe estar en contacto directo con fuentes lo más variadas posible, aprender a diferenciarlas, saber de qué tipo son, saber buscarlas, ordenarlas y clasificarlas. En definitiva, el alumnado debe aprender a ser competente en la lectura de las fuentes, cosa que le permitirá descubrir la información que el objeto lleva consigo y, para ello, debemos propiciar en los alumnos una mentalidad indagatoria y también crítica (Prats y Santacana, 2011). 
Por otra parte, la propuesta educativa de montaje de una exposición museográfica se basa en los principios que el museólogo debe tener presente, acorde con Santacana y Llonch (2008). Según uno de estos principios, las exposiciones deben construirse a partir de temas cotidianos y mediante objetos que las personas poseen en sus casas. Gracias a los objetos que todos tenemos en nuestro hogar podemos abarcar una infinidad de temas, relatar momentos históricos diversos y dar respuesta a determinados problemas "mostrando cómo no siempre son nuevos, poniendo de manifiesto cómo fueron afrontados en el pasado, qué repercusiones tuvieron y cómo deberían ser afrontados hoy" (Santacana y Llonch, 2008, p. 111).

En resumen, los objetos del pasado son fáciles de utilizar, son significativos y permiten reconstruir momentos concretos de la historia, así como relacionarlos a procesos de cambio y procesos evolutivos. En consecuencia, son un instrumento ideal para la enseñanza-aprendizaje en la asignatura de Historia.

En segundo lugar, la experiencia didáctica está vinculada a la teoría y la práctica sobre museos de aula, de largo recorrido y con una extensa bibliografía tanto teórica como empírica, desarrolladas principalmente en aulas de educación infantil y primaria (Barnsdale-Paddok y Harnett, 2002; Cooper, 1995; Kerrigan, 2001; Murphy, 2005; Schmidt y García, 2007; Singer y Singer, 2004; Solé, 2012a, 2012b).

En tercer lugar, la experiencia docente que se presenta en este trabajo se basa en lo que se conoce como m-learning (mobile learning), un método de enseñanza-aprendizaje basado en el uso de dispositivos móviles. "Es necesario introducir el uso de los teléfonos móviles en materia educativa patrimonial si queremos estar al pie del cañón; de lo contrario, estaremos educando en un lenguaje y con unos instrumentos ya caducados para nuestros jóvenes" (Santacana y Coma, 2014 , p. 12). El concepto de m-learning surge del aprovechamiento del máximo exponente hoy en día en tecnología móvil, es decir, el teléfono móvil tipo Smartphone. Este aparato, que actualmente casi todos llevamos encima continuamente, es, según afirman Santacana y Coma (2014), un instrumento útil para fijar imágenes y conceptos, comparar, informarse, verificar datos, favorecer el pensamiento analítico, hacer fluir la información, el intercambio permanente y una continua puesta al día. En definitiva, el teléfono móvil es un sistema de retroalimentación inmediata, instantánea, masiva y entretenida. Sin embargo, el uso del teléfono móvil como instrumento de aprendizaje no debe hacerse con el mero propósito de introducir la tecnología, sino que debemos pensar a quién se dirige, el objetivo de su uso, los contenidos (conceptos, procedimientos y valores) que queremos trabajar, etcétera (Llonch y Martín, 2016; Ortega y Pérez, 2016).

En cuarto y último lugar, la experiencia persigue también el desarrollo del pensamiento histórico de los futuros docentes, sobre el que en los últimos años se han desarrollado distintos trabajos, tanto en formación de maestros como del profesorado de secundaria (Pagès, 2009; Sáiz y Gómez, 2016; Sáiz y López-Facal, 2015; Santisteban, 2010; Santisteban, González y Pagès, 2010).

\section{Desarrollo de la experiencia}

La experiencia de innovación docente que presentamos se desarrolló en el Grado de Educación Primaria de la UdL. En ella participaron un total de seis grupos-clase, cada uno formado por una media de 30 alumnos, e implicó la participación de 173 estudiantes. Estos, a su vez, se dividieron posteriormente en subgrupos, resultando así la cantidad final de 36 grupos de trabajo constituidos por entre cuatro y seis alumnos cada uno.

La secuencia didáctica empezó con un seminario de iniciación a la edición de imágenes y vídeos. En primer lugar, bajo el título "Recursos digitales para educadores", se llevó a cabo una sesión compuesta por tres partes: (1) conceptos básicos sobre imagen digital, (2) grandes colecciones online como fuente de inspiración y (3) ejercicios prácticos sobre retoque fotográfico. Posteriormente, se realizó un seminario de dos sesiones acerca de la edición de vídeos, en las cuales los alumnos aprendieron recursos sobre cómo mezclar fuentes primarias de diversa naturaleza para elaborar una fuente secundaria (por ejemplo, creando un documento audiovisual 
subtitulado o con voz en off a partir de fotografías). Con todo ello, se pretendía que los futuros maestros profundizasen en el conocimiento y uso de las fuentes, aprendiesen a diferenciarlas, a clasificarlas y a manipularlas según un juicio crítico. Además, se pretendía mostrarles ejemplos de recursos digitales y dotarlos de herramientas que pudieran poner en práctica para posteriormente crear sus propios recursos didácticos a partir de fuentes primarias.De manera paralela al seminario, se procedió a escoger la temática de la exposición a partir de los objetos que el alumnado había analizado en un trabajo previo. A través de un mapa conceptual que se plasmó en la pizarra, se pusieron en común los objetos y las inducciones que de estos trabajos previos se habían derivado. A partir de la visualización del mapa se procedió a agrupar los objetos y las inducciones en posibles temas vinculados al currículum de ciencias sociales. A continuación, cada grupo-clase, a través del debate, consensuó el tema sobre el que versaría la exposición efímera. Los temas que se acordaron en cada grupo-clase fueron los siguientes: el papel de la mujer entre los años 20 y 60 del s. XX; la educación en Cataluña entre los años 30 y 70 del s. XX; la Guerra Civil, entre la vida militar y la vida cotidiana; la vida cotidiana durante la primera mitad del s. XX, y la vida en el campo y la vida en la ciudad durante el período de la Guerra Civil.

Una vez que cada grupo-clase hubo escogido una temática, se introdujo a los alumnos en el método tradicional de clasificación de fuentes históricas, es decir, mediante la creación de fichas perforadas de clasificación en cuartillas de cartulina. La finalidad era crear una base de datos de las fuentes primarias relacionadas con la temática elegida por el grupo-clase y que cada alumno había buscado en su entorno. Cada fuente seleccionada debía tener su ficha, en la que constaban los datos de identificación de la fuente (tipo de fuente, año de creación, autor, etcétera), una descripción exhaustiva (qué es, para qué servía, quién la utilizaba, en qué contexto se situaba, quién la había creado, etcétera) y también una fotografía de la fuente, que previamente los alumnos debían manipular mediante algún programa de edición de imágenes para mejorar la calidad de la imagen (perspectiva, nitidez, iluminación, retoque de fondo, etcétera) (Figura 1). Durante las semanas en las que se realizaron las fichas clasificatorias, los estudiantes traían los objetos al aula -en la medida de lo posible- para compartirlos con el resto de compañeros; además, aquellos subgrupos que disponían de mayor número de fuentes las compartieron con los que tenían menos para que así todos pudiesen practicar este sistema de clasificación de fuentes.

El paso siguiente consistió en que, a partir de las fuentes reflejadas en las fichas clasificatorias, cada subgrupo concretase la subtemática sobre la cual se centraría su ámbito expositivo. A partir de aquí, el trabajo tuvo una doble vertiente, por una parte, la búsqueda de información y documentación acerca de la subtemática escogida (donde cabía la búsqueda de otras fuentes primarias o bien fuentes secundarias de todo tipo como libros, carteles, recursos artísticos, vídeos, documentales...) y la posterior selección de aquellas dos o tres ideas clave que el grupo considerase importante transmitir. Por otra parte, la creación de recursos digitales con los que transmitir esas ideas principales de manera creativa, usando las fuentes primarias y secundarias encontradas y en forma de imagen o vídeo (ya que habían sido los recursos trabajados en los seminarios). Los recursos digitales creados estarían presentes también en la exposición efímera, pues las cartelas que acompañarían a las piezas de la exposición no serían cartelas convencionales, sino códigos QR que el público asistente podría escanear con su móvil o tableta. Mediante estos QR, el visitante accedería a los diferentes recursos digitales creados por los alumnos. Para introducir a los futuros docentes en el uso de dichos códigos, se desarrolló un tercer seminario con los objetivos de (1) dar a conocer en qué consisten los códigos QR, (2) analizar modelos ya en funcionamiento, (3) conocer diferentes aplicaciones en línea de creación de códigos QR, (4) conocer y descargar aplicaciones de lectura de códigos con el teléfono móvil o tableta y (5) realizar algunos ejercicios prácticos de creación y lectura de códigos. 


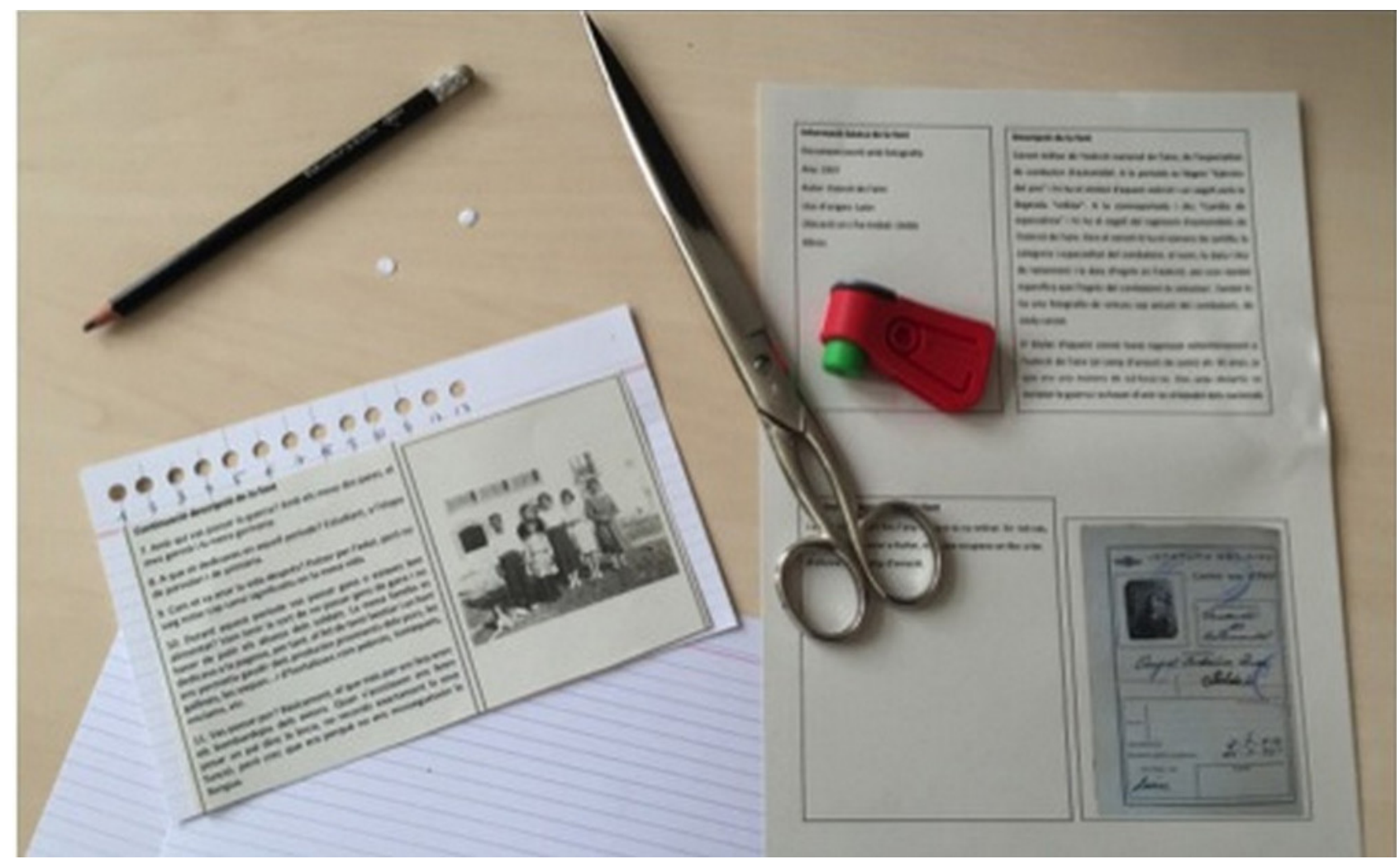

Figura 1: imagen de las sesiones sobre clasificación de fuentes a través de fichas perforadas.

Fuente: elaboración propia.

Finalmente, y tras unas sesiones de trabajo libre por parte de los alumnos con la tutorización del docente, se realizaron seis exposiciones efímeras (una por cada grupo-clase). Cada subgrupo escogió una de las fuentes primarias con las que había estado trabajando a lo largo de la experiencia didáctica, la que consideró más significativa de la subtemática escogida, para que fuese el elemento central de su ámbito expositivo. Así pues, estas fuentes fueron las piezas que se encontraron físicamente en la exposición, junto con algún cartel expositivo, siendo virtuales el resto de información y recursos.

\section{Resultados de la experiencia}

\subsection{Lupa de aumento sobre un ejemplo: "La alimentación durante la Guerra Civil española y la posguerra"}

Para presentar un nivel mayor de concreción de la experiencia realizada, recogemos el trabajo desarrollado por un grupo compuesto por cuatro miembros y que se encontraba dentro del grupoclase que desarrolló la temática "La vida en el campo y en la ciudad durante el período de la Guerra Civil".

En la fase de búsqueda de fuentes primarias del entorno, el grupo consiguió reunir un total de 13 fuentes, todas ellas pertenecientes a su entorno más cercano. Así pues, en la fase de clasificación, realizaron 13 fichas clasificatorias de fuentes de diversa índole, como se puede ver a continuación:

- Dos documentos escritos: un certificado con sello del régimen franquista que señalaba que el titular había superado con éxito el servicio militar y la portada de un periódico publicado clandestinamente en 1936.

- Dos documentos escritos con fotografía: un carnet militar del ejército de aire y un carnet 
provisional de excombatiente en la Guerra Civil.

- Cuatro objetos: un aparato de radio datado entre 1940 y 1950, una maleta de alrededor de 1940 perteneciente a un conscripto español, un mortero datado de 1930 aproximadamente y un billete de 50 céntimos de peseta emitido por el Ayuntamiento de Barcelona en el año 1937.

- Una fotografía de un grupo de soldados uniformados, tomada en la localidad de Figueres entre 1937 y 1940.

- Una fotografía de una edificación: un búnker de la Guerra Civil situado en el municipio de Cubelles.

- Tres testimonios orales que narran cómo vivieron (en diversos aspectos de la vida cotidiana) la Guerra Civil y la posguerra en Cataluña, pero cada uno en un contexto diferente (en un pueblo del Pirineo, en un pueblo cercano a Barcelona y en la ciudad de Lleida).

En la siguiente fase de elección de una subtemática relacionada con la temática del grupoclase, este grupo escogió centrarse en el tema de la alimentación. Para la elección de la subtemática, que no fue fácil, fueron determinantes las fuentes orales, ya que algunos de los aspectos que destacaronn los entrevistados eran el hambre que recordaban haber sufrido, la falta de variedad de alimentos que recordaban de su infancia, las cartillas de racionamiento, el negocio del estraperlo, etc. Como el tema de la alimentación se había trabajado en otros proyectos tanto de la misma asignatura como de otras materias, el grupo lo consideró una subtemática interesante. Así pues, se procedió a recabar más información de otras fuentes, tanto primarias como secundarias, acerca de la alimentación durante la Guerra Civil y la posguerra, así como sobre los diversos canales de aprovisionamiento que surgieron en España durante la época de Guerra Civil y la posguerra. A partir de estas fuentes de información, el grupo creó los siguientes recursos basados en las ideas que se explicitan:

- Un vídeo de imágenes y voz en off donde se explicaba el régimen de racionamiento de alimentos básicos establecido en el año 1939 por orden ministerial (la aparición de las cartillas de racionamiento y sus categorías, los alimentos racionados y las cantidades a las que la población tenía derecho por semana, la problemática de la mala calidad de los productos, la aparición del pan negro, tan característico de este período de nuestra historia y el fin del racionamiento de alimentos en el año 1952).

- Una recopilación de testimonios escritos acerca de los diversos intercambios surgidos en esa época, los cuales hicieron que la alimentación superase su función estrictamente nutricional y adquiriese un valor simbólico, transformando el acto alimentario de un hecho meramente fisiológico a un acto de construcción de la propia identidad y de reproducción de los valores de un grupo social enmarcado en un determinado contexto; intercambiando no solo alimentos por alimentos, sino alimentos por ropa, por asistencia sanitaria, por trabajos domésticos, etcétera.

- Un vídeo con dos testimonios orales que explicaban en primera persona la forma de comercio nacida en la posguerra como consecuencia del racionamiento de alimentos básicos, conocida como estraperlo.

- Asimismo, fueron recogidos de las redes sociales otros dos testimonios orales acerca de la ingesta de lentejas durante la Guerra Civil y la posguerra, plato al que se le dio el nombre de "Píldoras del Doctor Negrín", en honor a Juan Negrín López, médico, político y presidente del gobierno de la Segunda República que luchó por apartar a España de las políticas fascistas de Hitler y Mussolini.

- Otro recurso propuesto fue la publicación titulada "Cocina de recursos", publicado por primera vez en 1941 y reeditado en 2011 al fervor de la reciente crisis económica (Doménech, 2011). Se trata de un libro que recopila las recetas surgidas en España durante la Guerra Civil y la posguerra a causa de la escasez de determinados alimentos, por ejemplo, los calamares de la huerta (sin calamar) o la sopa de pobres a la marsellesa (que se hacía hirviendo todo tipo de restos de comida).

Mediante este último elemento se transmite la idea de que, en situaciones de penuria, el ser humano es capaz de introducir variaciones en sus costumbres, sacar el máximo rendimiento de los recursos al alcance y adaptarse a la nueva situación. Para la exposición museográfica, el grupo consideró que esta era la idea clave que quería transmitir a través del objeto físico expuesto. Sin 
embargo, el grupo no escogió una de las fuentes primarias recabadas a lo largo de la secuencia didáctica, sino que decidió crear su propia fuente. De este modo, elaboraron una de las recetas surgidas del ingenio de la población en situación de crisis, en este caso, la tortilla de patata sin huevo ni patata. Así pues, en la exposición efímera, el grupo expuso austeramente su tortilla (Figura 2), acompañada de servilleta, plato y taza (utensilios que databan entre los años 40-50). Asimismo, el grupo se proveyó de una segunda tortilla cortada a tacos, invitando al público a degustar el alimento.

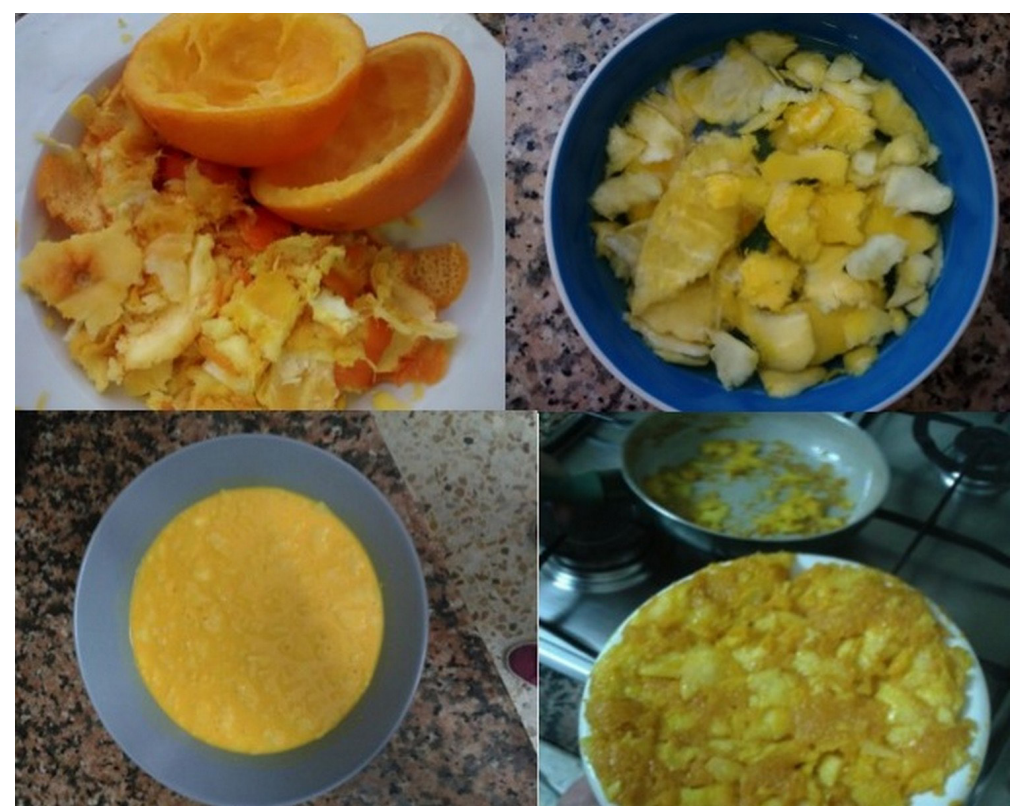

Figura 2: composición del proceso de "creación" de la tortilla de patatas sin huevo ni patata, hecha fundamentalmente a base de harina y piel de naranja. Fuente: elaboración propia.



Figura 3: imagen del ámbito expositivo sobre alimentación durante la Guerra Civil y la posguerra. Fuente: elaboración propia. 
Por otra parte, la pieza iba acompañada de un cartel con el título "La alimentación durante la Guerra Civil española y la posguerra" (Figura 3). Este cartel también incluía seis códigos QR, con los títulos "Las cartillas de racionamiento", "El intercambio", "El estraperlo", "Las píldoras del Dr. Negrín", "Alimentando la imaginación" y "La tortilla de patata sin huevo ni patata". Además, los códigos QR se hicieron mediante una aplicación que permitía ir más allá del formato QR convencional en blanco y negro (Figura 4). Todos los códigos QR que acompañaban a la pieza expuesta remitían al público visitante a los recursos creados por el grupo y que hemos indicado anteriormente. Todos estos recursos, a su vez, se recogieron en un blog que el grupo denominó "Pa negre" (https://panegreudl. wordpress.com/), haciendo referencia a este alimento surgido durante la época en torno a la cual giraba la exposición y que ha dado título a uno de los éxitos cinematográficos del cine nacional de la última década, premio Goya a la mejor película en 2010 (Figura 5).

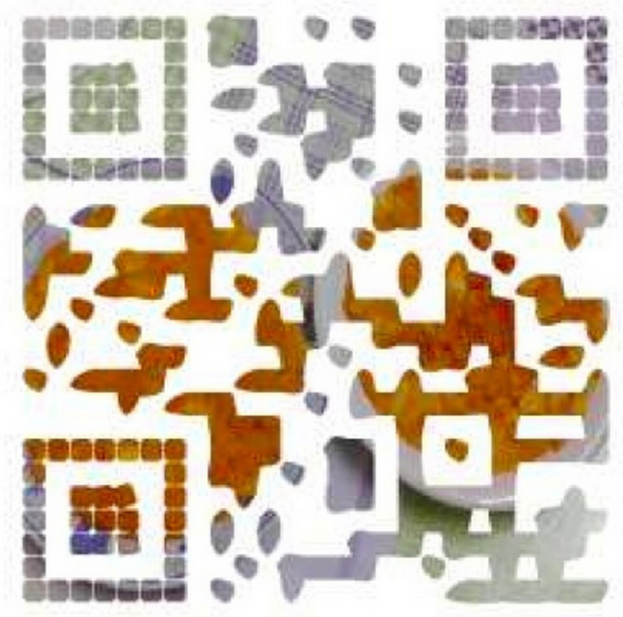

Figura 4: detalle de uno de los códigos QR cuyo diseño presenta en el fondo la tortilla de patatas sin huevo ni patatas. Fuente: elaboración propia

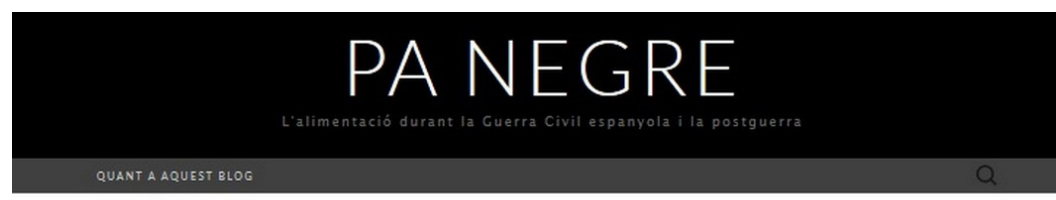

LES CARTILLES DE RACIONAMENT

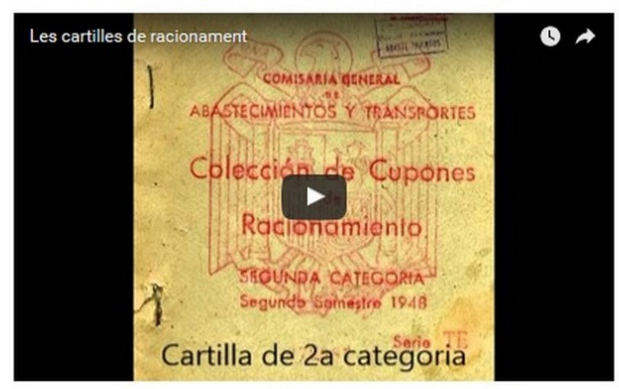

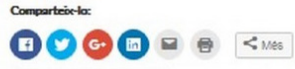

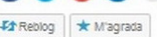

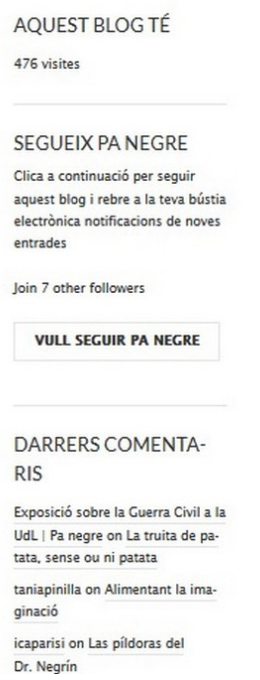

Dr. Negrin

Figura 5: captura de pantalla del blog "Pa negre". 
Finalmente, una vez acabada la exposición, el grupo añadió al blog una entrada en referencia a la exposición realizada, explicando cuál era su temática, sus singulares características y las subtemáticas que en ella se pudieron ver, acompañadas por imágenes de todas las piezas expuestas y los correspondientes códigos QR.

\subsection{Resultados de aprendizaje}

El desarrollo de esta experiencia de innovación docente, tal y como se muestra en el ejemplo que se ha expuesto, pone de manifiesto la consecución de una serie de competencias tanto vinculadas al aprendizaje de la historia y al desarrollo del pensamiento histórico como otras competencias transversales que se exigen a los futuros maestros.

El resultado principal de la experiencia tiene que ver con el hecho que facilita el desarrollo, si bien en muy distinta medida, de los cuatro aspectos relacionados con las competencias de pensamiento histórico que presentan Santisteban, González y Pagès (2010, p. 2) :

- La conciencia histórico-temporal

- La representación de la historia a través de la narración y de la explicación histórica

- La empatía histórica y las competencias para contextualizar

- La interpretación de la historia a partir de las fuentes

Es evidente que el que más se trabaja es el último, ya que en esta experiencia se parte de las potencialidades de la didáctica del objeto y del análisis en profundidad de las fuentes objetuales para acabar analizando e interpretando todo tipo de fuentes primarias y reconstruyendo a través de ellas pequeños fragmentos del pasado que son presentados a través de recursos digitales y en forma de exposición museográfica al resto de compañeros. Por tanto, con esta experiencia, se hace partícipe al alumnado del conocimiento del proceso de trabajo de la ciencia histórica a través de sus testimonios y se facilita la ruptura con modelos tradicionales de enseñanza-aprendizaje de la historia a través de relatos cerrados construidos y sin prácticamente contacto con las fuentes primarias del pasado.

Al mismo tiempo, consideramos que la experiencia también contribuye a trabajar la empatía histórica. En el ejemplo que se ha presentado hay una evidente intención de comprender y contextualizar las vicisitudes vinculadas a las penurias alimentarias que se vivieron durante la Guerra Civil y la posguerra, de ponerlas de manifiesto e incluso de experimentar con algunas de las recetas de la "Cocina de recursos", así como hacer que sus compañeros las experimentaran -ya que, recordamos, finalmente el eje central de su ámbito museográfico sobre "La alimentación durante la Guerra Civil española y la posguerra" fue la tortilla de patatas sin huevo ni patatas que cocinaron para que sus compañeros pudieran degustar.

En cuanto a la conciencia histórico-temporal, creemos que esta propuesta de innovación educativa permite desarrollarla, si bien en el ejemplo presentado se ve reflejada de manera más bien anecdótica, sobre todo al reflexionar entorno a la capacidad humana en todos los tiempos, incluso el presente, de adaptarse a nuevas situaciones en momentos de crisis y extraer el máximo rendimiento de los recursos al alcance.

Respecto a la representación de la historia a través de la narración y de la explicación histórica, aunque en el ejemplo planteado se ve poco reflejada, cabe recordar que la finalidad última de la propuesta de innovación es crear una exposición museográfica sobre una temática histórica y para cada ámbito o subtemática se crean recursos digitales cuyo elemento fundamental es el mensaje e idea que transmiten. Por lo tanto, lo fundamental es la narrativa elaborada por cada grupo para explicar cada idea, mientras que el recurso digital es el modo de transmitirla. Respecto al resto de competencias que se llevan a la práctica en esta propuesta son muchas y ponen de manifiesto la transversalidad implícita en las acciones educativas de enseñanza-aprendizaje de la historia. Así pues, a través de la experiencia presentada, el alumnado trabaja competencias digitales que le permiten conocer programas de edición de fotografías y de vídeos y poner en práctica los conceptos aprendidos al respecto; además, les permite conocer sistemas basados en 
la presentación de información a través de tecnología móvil que, aunque sencillos, tienen gran aplicabilidad en distintos ámbitos educativos. Otra competencia muy desarrollada es la de buscar información y sistematizarla en forma de mapas conceptuales, competencia que enlaza con el trabajo desarrollado en otras áreas y asignaturas del Grado. También favorece el trabajo en equipo, tanto a nivel de grupo clase como de pequeños grupos de trabajo y se pone mucho énfasis en la toma de decisiones conjunta y democrática, ya que la elección de las temáticas de la exposición se realizó por votación tras un pequeño debate entre los partidarios de las distintas "candidaturas" temáticas. Por último, también hay que tener en cuenta que cualquiera de los temas históricos trabajados implica establecer conexiones con conocimientos de otras áreas (dietética, higiene, física, etc.) y facilita recuperar proyectos y trabajos ya desarrollados a lo largo del Grado en Educación Primaria, con lo que se facilita, por un lado, profundizar en temas ya estudiados y, por otro, establecer conexiones interdisciplinares y abordar temáticas similares desde puntos de vista distintos.

\section{Reflexiones finales}

La experiencia docente que aquí se ha relatado y los resultados de aprendizaje obtenidos en el trabajo de los alumnos ponen de manifiesto que, bajo el pretexto de la creación colaborativa de recursos didácticos digitales de contenido histórico, el alumnado desarrolla diversas competencias (de obtención de conocimiento histórico, así como procedimentales) que les sirven tanto para su aprendizaje sobre la historia como para adquirir metodologías de enseñanza-aprendizaje de las ciencias sociales y la historia.

Entre muchos otros aspectos, en primer lugar, el alumnado se aproxima a su patrimonio más cercano (tanto familiar como local), y a partir de éste descubre contenidos de diversa índole, entre ellos históricos, vinculados a dicho patrimonio. En segundo lugar, aprende a generar conocimiento desde lo concreto (las fuentes primarias) hasta lo abstracto (conocimientos históricos y práctica del método inductivo). En tercer lugar, el alumnado va de lo particular a lo general, puesto que a través de las fuentes familiares o de historia local establece conexiones con el contexto más general. En cuarto lugar, desarrolla competencias de búsqueda y selección crítica de información. En quinto lugar, conoce una técnica de clasificación de fuentes a través de fichas perforadas que es el fundamento para crear bases de datos manuales y que permite comprender el sistema de clasificación que puede ser el paso previo para aprender a emplear programas de creación de bases de datos. En sexto lugar, conoce y experimenta una estrategia didáctica de largo recorrido: el museo de aula. En séptimo lugar, descubre el potencial educativo de los dispositivos móviles. $Y$ en último lugar, desarrolla algunas competencias de pensamiento histórico, especialmente la de formas de representación de la historia y la de interpretación histórica, donde el trabajo con fuentes del pasado es fundamental, además de otras competencias transversales.

Creemos firmemente que solo cuando los maestros en formación inicial experimentan en primera persona esta acción educativa se está favoreciendo que cuando ejerzan su tarea profesional apliquen técnicas de enseñanza-aprendizaje colaborativo, trabajen de modo inter- y transdisciplinar, sean capaces de crear sus propios recursos didácticos (y que estos, a su vez, sean de una naturaleza con la que sus alumnos se identifiquen), promuevan la capacidad de búsqueda crítica de información y recursos de sus alumnos y entiendan el patrimonio más cercano como fuente de información del pasado y de comprensión del presente, con una proyección que trasciende el entorno más próximo. Por ello, suscribimos las palabras de Santisteban (2010, p. 35) cuando afirma que

Una de las finalidades más importantes de la enseñanza de la historia es formar el pensamiento histórico, con la intención de dotar al alumnado de una serie de instrumentos de análisis, de comprensión o de interpretación que le permitan abordar el estudio de la historia con autonomía y construir su propia representación del pasado, al mismo tiempo que pueda ser capaz de contextualizar o juzgar los hechos históricos, consciente de la distancia que los separa del presente. En todo caso, la formación del pensamiento histórico ha de estar al servicio de una ciudadanía democrática, que utiliza 
la historia para interpretar el mundo actual y para gestionar mejor el porvenir.

Para ello, es imprescindible que el sistema educativo vele por aportar profesionales de la educación primaria y secundaria conscientes de la importancia de formar el pensamiento histórico, tanto como método de enseñanza-aprendizaje de la historia, como con la finalidad mucho más ambiciosa de crear ciudadanos críticos, autónomos y con multiplicidad de recursos para hacer frente al futuro.

\section{Bibliografía}

Adams, C. y Miller, S. (1982). Museums and the Use of Evidence in History Teaching. Teaching History, 34, 3-6.

Arias, L., Casanova, E., Egea, A., García, A. B., y Morales, M. a J. (2016). Aprendiendo a tocar la historia. Las fuentes objetuales como recurso de aprendizaje en Educación Infantil y Primaria. En R. López-Facal (Org.). Ciencias sociales, educación y futuro: Investigaciones en didáctica de las ciencias sociales (pp. 136-148). Santiago de Compostela: Red 14-Universidad de Santiago de Compostela.

Aguiar, L. (2015). Ver, Tocar e Sentir a Maia: um projeto de Mediação Patrimonial no Museu de História e Etnologia da Terra da Maia. Trabajo Final de Máster en Museología. Porto: Faculdade de Letras da Universidade do Porto.

Alvarado, A. E. y Herr, P. R. (2003). Inquiry-based learning using everyday objects: Hands-on instruction strategies that promote active learning in grades 3-8. Thousand Oaks: Corwin Press Inc.

Bardavio, A. y González, P. (2003). Objetos en el tiempo. Las fuentes materiales en la enseñanza de las Ciencias Sociales. Barcelona: ICE Universidad de Barcelona-Horsori.

Barnsdale-Paddok, L. y Harnett, P. (2002). Promoting play in the classroom; children as curators in a classroom museum. Primary History, 30, 19-21.

Corbishley, M. (2011). Pinning down the past: archaeology, heritage, and education today.

Woodbridge, Suffolk, UK - Rochester, NY: Boydell Press.

Cooper, H. (1995). History in the Early Years: Teaching and Learning in the first three Years of School. London: Routledge.

Cooper, H. (2005). The Teaching of History in Primary Schools- Implementation the Revised National Curriculum (3rd Ed.). London: David Fulton.

Cuenca, J. M. y Estepa, J. (2005). La caja genealógica: fuentes y tiempo en Educación Infantil. Una propuesta para trabajar con maestros. Quaderns Digitals, 37. Recuperado de php?accionMenu=hemeroteca. VisualizaArticulolU.visualiza\&articulo id $=8416$

Doménech, I. (2011). Cocina de recursos (Deseo mi comida). Gijón: Trea.

Durbin, G., Morris, S. y Wilkinson, S. (1996). A Teacher's Guide to Learning from Objects. London: English Heritage.

Egea, A. y Arias, L. (2013). IES Arqueológico: La arqueología como recurso para trabajar las competencias básicas en la educación secundaria. Clío: History and History Teaching, 39, Recuperado de http://clio.rediris.es/.

Egea, A. y Arias, L. (2015). La arqueología llega a las aulas. Objetos y otras fuentes primarias para la enseñanza de la historia. En G. Solé (coord.), Educação Patrimonial: contributos para a construção de uma consciência histórica (pp. 151-169). Braga: Centro de Investigação em Educação (CIEd) - Instituto de Educação, Universidade do Minho.

Éthier, M-A., Demers, S. y Lefrançois, D. (2010). Las investigaciones en didáctica sobre el desarrollo del pensamiento histórico en la enseñanza primaria. Una panorámica de la literatura publicada en francés e inglés desde el año 1990. Enseñanza de las Ciencias Sociales, 9, 61-73.

Fernandes, C. (2009). A explicação histórica com base nos artefactos: Um estudo com alunos do $3^{\circ}$ ciclo do ensino básico. Trabajo Final de Máster en Supervisión de la Enseñanza de Historia y 
ciencias Sociales. Braga: Universidade do Minho.

Gómez, C. J. y Miralles, P. (2015). ¿Pensar históricamente o memorizar el pasado? La evaluación de los contenidos históricos en la educación obligatoria en España. Revista de Estudios Sociales, 51, 52-68. DOI: 10.7440/res52.2015.04.

Gómez, C. J., Ortuño, J. y Molina, S. (2014). Aprender a pensar históricamente. Retos para la historia en el siglo XXI. Revista Tempo e Argumento, 6 (11), 5-27.

Gómez, C. J. y Rodríguez, R. A. (2014). Aprender a enseñar ciencias sociales con métodos de indagación. Los estudios de caso en la formación del profesorado. REDU: Revista de Docencia Universitaria, 12 (2), 307- 325.

Hawkes, A. (1996). Objects or Pictures in the Infant Classroom? Teaching History, 85, 30-35.

Harnett, P. (2006). Shared Heritages? Investigating Ways of life in the Past to promote European Consciousness with Children in Primary schools. En A. Ross (Ed.), Citizenship Education: Europe and the World (pp.169-174). London: CiCe.

Hoodless, P. (1996). Time and Timelines in the Primary School. London: Historical Association.

Inarejos, J. A. (2017). El uso de fuentes históricas y bases documentales en la formación del profesorado de Educación Infantil y Primaria. Revista Electrónica Interuniversitaria de Formación del Profesorado, 20(2), 157-166.

Kerrigan, S. (2001). Creating a community school museum: theory into practice. Internacional Journal of Historical Learning, Teaching and Research, 2(1), 1-7.

Levstik, L., Henderson, A. G. y Lee, Y. (2014). The Beauty of Other Lives: Material Culture as Evidence of Human Ingenuity and Agency. The Social Studies, Philadelphia, 105(4), 184-192.

Levstik, L., Henderson, A. G. y Schlarb, J. S. (2008). Digging for clues: An archaeological exploration of historical cognition. En L. S. Levstik y K. C. Barton, Researching History Education. Theory, Method, and Context (pp. 393-407). New York: Routledge.

Llonch, N. (2017). Propuesta de modelo de enseñanza-aprendizaje de la historia en formación de maestros/as a través de la didáctica del objeto. REDU. Revista de Docencia Universitaria, 15(1), 147-174. DOI: 10.4995/redu.2017.5994.

Llonch, N., Alonso, N. y Benito, P. (2015). Hacer visible lo invisible: dando voz a las personas y sus espacios desde la didáctica de la Historia en el grado de Educación Primaria. En A. M. Hernández, C. R. García y J. L. de la Montaña (Eds.), Una enseñanza de las ciencias sociales para el futuro: Recursos para trabajar la invisibilidad de personas, lugares y temáticas (pp. 535-543). Cáceres: Universidad de Extremadura y AUPDCS.

Llonch, N. y Martín, C. (2016). Los códigos QR y su potencial como herramienta de educación patrimonial interdisciplinar en las aulas. En M. Guzmán (Ed.), Patrimonio y educación. Una propuesta integradora (Vol. 1) (pp.167-177). Granada: Universidad de Granada y AUPDCS.

Llonch, N. y Molina, E. (2012). Del desván a la escuela. Investigar la educación para la ciudadanía basada en el patrimonio: el aula como museo. En N. de Alba, F. F. García-Pérez y A. Santiesteban (Eds.), Educar para la participación ciudadana en la enseñanza de las Ciencias Sociales, (Vol. 2), (pp. 27-34). Sevilla: Díada.

Llonch, N. y Parisi-Moreno, V. (2016). Contribuciones a la didáctica de la Historia a través del método de análisis del objeto: como ejemplo... una "vasulla". Panta Rei: revista de ciencia y didáctica de la historia, 8, 111-124.

Mendioroz-Lacambra, A. (2016). Propuesta formativa en el grado de maestro de Educación Infantil, para trabajar el método de investigación histórica en el aula. Arte, Individuo y Sociedad, 28(3), 399-414. DOI: 10.5209/rev ARIS.2016.v28.n3.42597

Murphy, J. (2005). 100 ideas for teaching history. Londres: Continuum.

Nulty, P. (1998). Talking about artefacts at Key Stage 1. En P. Hoodless (Ed.), History and English in Primary School: Exploting the Links (pp. 20-34). London: Routledge.

Ortega, D. y Pérez, C. (2016). Didáctica del patrimonio histórico-cultural y TICD: códigos QR en la formación de maestros/as. En M. T. Tortosa, S. Grau y J. D. Álvarez (Eds.), XIV Jornadas de Redes de Investigación en Docencia Universitaria. Investigación, innovación y enseñanza 
universitaria: enfoques pluridisciplinares (pp. 557-568). Alacant: Universitat d'Alacant, Institut de Ciències de l'Educació.

Pagès, J. (2009). El desarrollo del pensamiento histórico como requisito para la formación democrática de la ciudadanía. Reseñas de Enseñanza de la Historia, 7, 69-91.

Pinto, M. H. (2012). Educação histórica e patrimonial: conceções de alunos e professores sobre o passado em espaços do presente. Tesis de Doctorado en Educación, especialidad de Educación en Historia y Ciencias Sociales. Braga: Universidade do Minho.

Prats, J. y Santacana, J. (2011). Trabajar con fuentes materiales en la enseñanza de la Historia. En J. Prats (coord.), Geografía e Historia. Investigación, innovación y buenas prácticas (pp. 1137). Barcelona: Graó.

Prieto, J. A, Gómez, C. J. y Miralles, P. (2013). El uso de fuentes primarias en el aula y el desarrollo del pensamiento histórico y social. Una experiencia en Bachillerato. Clio. History and History Teaching, 39, 1-14.

Ribeiro, F. (2002). O pensamento arqueológico na sala de aula de História. Trabajo Final de Máster en Supervisión de la Enseñanza de Historia y ciencias Sociales. Braga: Universidade do Minho.

Sáiz, J. y Gómez, C. J. (2016). Investigar el pensamiento histórico y narrativo en la formación del profesorado: fundamentos teóricos y metodológicos. Revista electrónica interuniversitaria de formación del profesorado, 19(1), 175-190.

Sáiz, J. y López-Facal, R. (2015). Competencias y narrativas históricas: el pensamiento histórico de estudiantes y futuros profesores españoles de educación secundaria. Revista Estudios Sociales, 52, 87-101. DOI: 10.7440/res52.2015.06.

Santacana, J. y Coma, L. (2014). El m-learning y la educación patrimonial. Gijón: Trea.

Santacana, J. y Llonch, N. (2008). Museo local. La cenicienta de la cultura. Gijón: Trea.

Santacana, J. y Llonch, N. (2012). Manual de didáctica del objeto en el museo. Gijón: Trea.

Santisteban, A. (2010). La formación de competencias de pensamiento histórico. Clío \& Asociados (14), 34-56.

Santisteban, A., González, N. y Pagès, J. (2010). Una investigación sobre la formación del pensamento histórico. En R. Ávila, P. Rivero y P. Domínguez (coords.), Metodología en investigación en didáctica de las ciencias sociales (pp. 115-128). Zaragoza: Instituto Fernando el Católico.

Schmidt, M. A. y García, T. B. (2007). O trabalho com objetos e as possibilidades de superação do sequestro da cognição histórica: estudo de caso com crianças nas séries iniciais. En M. A. Schmidt y T. B. García (Eds.), Perspectivas de Investigação em Educação Histórica (Vol. 1) (pp. 52-57). Curitiba: UFPR.

Singer, J. y Singer, A. J. (2004). Creating a museum of family artifacts. Social Studies and the Young Learner, 17(1), 5-10.

Schools Council. Joint Working Party of Museums (1972). Pterodactyls and Old Lace: Museums in Education. Littlehampton: Littlehampton Book Services Ltd.

Seixas, P., Morton, T., Colyer, J. y Fornazzari, S. (2013). The big six: Historical thinking concepts. Toronto: Nelson Education.

Smardz, K. E., y Smith, S. J. (2000). The Archaeology Education Handbook: Sharing Past with Kids. Walnut Creek, CA: AltaMira Press.

Solé, M. G. (2012a). A museum in the classroom: learning History from objects. Primary History, 61, 20-22.

Solé, M. G. (2012b). O museu de sala de aula: aprender história com os objectos. En M. A. Schmidt (Ed.), Atas do XII Congresso Internacional Jornadas de Educação Histórica "Consciência Histórica e as novas tecnologias da informação e comunicação" (pp. 315-332). Curitiba: LAPEDUH.

Solé, M. G. y Llonch, N. (2016). Investigação sobre a transversalidade social, disciplinar e geográfica de um modelo de ensino-aprendizagem da história através de fontes objetuais e criação de museus de aula. Antíteses, 9(18), 87-117. 
Vella, Y. (2010). Artefacts in history education. Teaching History, 54, 6.

Vella, Y. (2011). Extending Primary Children's Thinking of the use of artefacts. International Journal of Historical Learning, Teaching and Research, 1(2), 1-11. 


\section{Panta Rei}

PANTA REI es una revista digital de investigación orientada a la Historia y otras ciencias afines. Su principal objetivo es la transmisión del conocimiento científico, dando una oportunidad también a los jóvenes investigadores que quieren abrirse camino en el estudio de las ciencias humanas y sociales. Se compone de estudios originales relacionados con la disciplina histórica así como su didáctica y difusión. Las diferentes secciones que componen la revista son: artículos de investigación, entrevistas a profesionales, recensiones de monografías de actualidad y crónicas de congresos o eventos científicos relevantes.

Todos los artículos publicados son objeto de un proceso de revisión a cargo de un mínimo de dos evaluadores, que se consideran expertos en el ámbito temático del artículo propuesto. Nuestro deseo es poder ofrecer unos contenidos rigurosos, de calidad y de interés.

EI CEPOAT (Centro de Estudios del Próximo Oriente y la Antigüedad Tardía de la Universidad de Murcia) es la institución encargada de la coordinación y gestión de la revista, desde donde anualmente se lanzará la convocatoria para aquellos que estén interesados en publicar sus trabajos, siempre relacionados con la Historia, Arqueología, Historia del Arte, Didáctica de las Ciencias Sociales, etc.

PANTA REI is a digital journal focused on History and other sciences related to it. Its main objective is the transmission of scientific knowledge by giving also an opportunity to young researchers who want to make their way in the study of human and social sciences. It is composed by original studies related to History, as well as its didactics and promotion. The different sections of this journal are: research articles, interviews to professionals, recensions on monographs about current issues and reports about congresses or relevant scientific events.

All the articles published are subject to a revision process carried out by a minimum of two reviewers who are considered to be experts in the field of the article proposed. Our wish is to offer rigorous contents with quality and being of interest to the reader.

CEPOAT (Centre of Studies of the Middle East and Late Antiquity of the University of Murcia) is the institution in charge of the coordination and management of this journal. This is the centre from where the call for papers will be launched for all the people interested in publishing their papers, always related to History, Archeology, Art History, Didactics of the Social Sciences, etc. 


\section{Normas de Publicación}

El autor se compromete a enviar trabajos originales, que no se encuentren publicados en otras revistas ni en otros idiomas. Así mismo, el mismo artículo no podrá ser presentado en otras revistas mientras dure el proceso de evaluación.

\section{Envío y presentación de originales}

Los artículos se enviarán exclusivamente a través del correo electrónico a la dirección pantarei@um.es. Los textos serán enviados en formato DOC y las imágenes en formato JPEG o TIFF, y con un tamaño mínimo de 2000 px. Éstas no aparecerán incorporadas en el texto, sino enviadas en archivo aparte y correctamente numeradas según su posición en el texto. Junto al trabajo, se rellenará y enviará un documento aparte en el que se especifiquen los datos del autor siguiendo el modelo disponible en la página Web de la revista.

Para la redacción de los trabajos se tendrá en cuenta el Manual de la American Psychological Association, en su sexta edición. La extensión máxima de los trabajos será de 30 páginas. La tipografía será Arial 11, con interlineado sencillo y sin espacio alguno entre párrafos. El texto deberá ir justificado a ambos márgenes y sin sangría en los primeros párrafos. Los márgenes serán de $2,50 \mathrm{~cm}$. En los casos en los que fuera necesario incorporar notas, éstas irán a pie de página, enumeradas consecutivamente, con tipografía Arial 10, interlineado sencillo y justificadas a ambos márgenes.

Una información más detallada se encuentra disponible en la página http://www.um.es/cepoat/ pantarei.

\section{Proceso de valoración y evaluación}

Una vez recibidos los trabajos, la Revista realizará una primera valoración. Si el trabajo enviado se ajusta a las normas de presentación propuestas, la temática es coincidente con la línea editorial de la revista y posee la calidad científica necesaria, será remitido al consejo asesor para una primera evaluación. Si no es así en este primer paso se puede rechazar directamente los documentos que incumplan claramente la línea editorial.

Será el Consejo Asesor quien indique a la revista la originalidad, relevancia, estructura, redacción, aparato bibliográfico, etc. del trabajo enviado y, para ello, se designará a dos revisores expertos externos que evaluarán cada uno de los trabajos, que pueden formar parte (o no) de este Consejo Asesor. La selección de los revisores se ajustará a la temática y características metodológicas del trabajo. El nombre y filiación de los autores serán eliminados del trabajo para su revisión, así como los revisores actuarán de manera anónima y confidencial.

Los revisores deberán rellenar un informe de evaluación que centrará su atención en aspectos tales como características formales, originalidad y novedad de los trabajos, relevancia de las propuestas y los resultados, calidad metodológica y validez científica.

Una vez terminado el proceso se decidirá la aceptación o no de los mismos y su publicación en el número que sea pertinente, así como las modificaciones susceptibles de ser realizadas para su final publicación. Dicha notificación se enviará únicamente por correo electrónico, en un plazo máximo de seis meses. 


\section{Publishing rules}

The author is committed to submit original papers not having been published in other reviews or in other languages. In this way, it is not allowed for the same paper to be presented in other reviews during the evaluation process.

\section{Submission and presentation of originals}

The articles will be exclusively submitted by email to pantarei@um.es. The texts will be submitted in DOC format and the images in JPEG or TIFF format, and with a minimum size of 2000 px. Images will not be integrated in the text but sent in another file and properly numbered according to their position in the text. Attached to the paper, a document will be filled out and sent where the author's data will be specified following the model available on the website.

The sixth edition of the Manual of the American Psychological Association will be taken into account for the writing of the papers. The length of the papers must not exceed 30 pages. Typography will be Arial 11 , with simple line spacing and no space between paragraphs. The text must be justified on both margins without indentation in the first paragraphs. Margins size will be $2.50 \mathrm{~cm}$. Where it could be necessary the incorporation of notes, they will be at the bottom of the page, consecutively numbered with typography Arial 10, simple line spacing and justified on both margins.

More detailed information is available on the website: http://www.um.es/cepoat/pantarei.

\section{Examination and assessment process}

The Journal will submit the papers to a first examination once received. If the paper follows the presentation guidelines, the subject agrees with the editorial line of this journal, and possess the scientific quality required, it will be sent to the advisory council for a first assessment. If not, the documents which clearly fail to complete the editorial line may be rejected straightaway in this first step.

The Advisory Council will indicate the originality, relevance, structure, writing, bibliography, etc. of the text to the journal; for this purpose, two outside experts will be designated to review the papers; these experts can be (or not) part of this Advisory Council. The selection of the experts will adjust to the subject and methodological characteristics of the paper. Name and affiliation of the author will be eliminated from the text for its review, in this way experts will act anonymously and confidentially.

The experts will fill out an assessment report which will focus on aspects such as formal characteristics, originality and novelty of the papers, relevance and results of the proposal, methodological quality and scientific validity.

Once the process is finished, the acceptance or not of the papers and its publication in the corresponding edition will be decided, as well as the modifications that may be done for its final publication. This notification will be sent by email within 6 months maximum. 


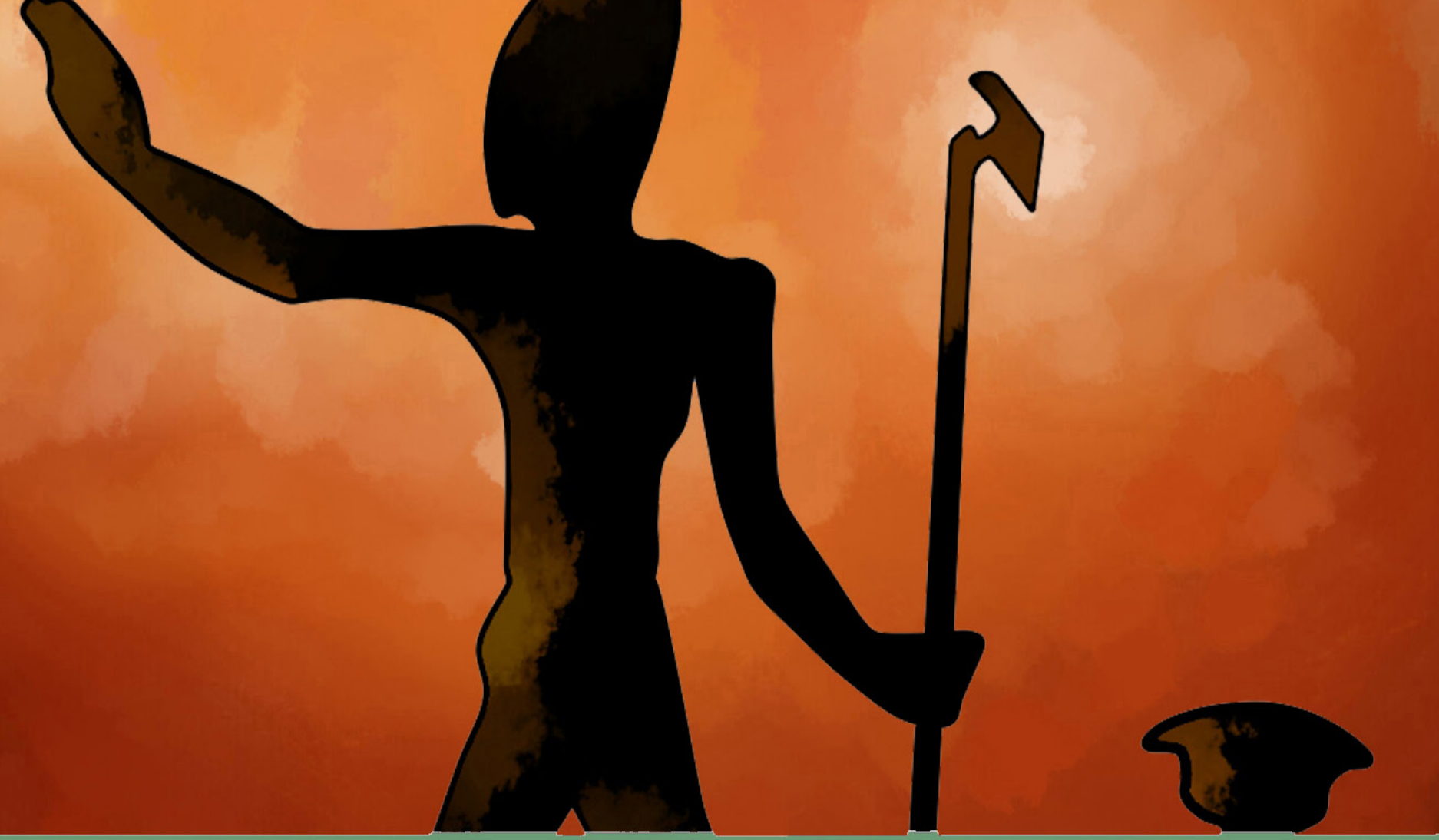

\section{cepot}

UNIVERSIDADD DE MURCIA

centro de estudios del

próximo oriente y la

antigüedad tardía 